\title{
Improved results for left-sided malignant colorectal obstruction with a proper selection for self expandable metal stent placement, surgical resection or diverting stoma
}

\author{
Antonio V. Sterpetti, Paolo Sapienza, Enrico Fiori, Luca DI. Marzo, Antonietta Lamazza* \\ University of Rome Sapienza, Italy
}

\section{A R T I C L E I N F O}

\section{Article history:}

Received 1 November 2019

Received in revised form

17 June 2020

Accepted 15 July 2020

Available online $\mathrm{xxx}$

\section{Keywords:}

Endoscopic stenting

Malignant colorectal obstruction

Colorectal cancer

\begin{abstract}
A B S T R A C T
Aims: Endoscopic placement of Self Expandable Metal Stents to relieve malignant colorectal obstruction has become a common therapeutic advancement in clinical practice.

Methods: In a 16 year period 145 patients had endoscopic placement of a Self-Expandable Metal Stent for acute/subacute left sided malignant colorectal obstruction in a center where gastroenterologists and surgeons cooperate in a daily basis, discussing indications.

Results: There was no operative mortality and no major complication in placement of the stent. Technical and clinical success was respectively $94.5 \%$ and $91.8 \%$. Consultation among specialists changed the preoperative indication in 60 patients.

Conclusions: Self-Expandable Metal Stents placement represents an important tool to treat patients with obstructing colorectal cancer. Surgical resection, diverting stoma or endoscopic stent placement should be chosen according to the clinical characteristics of each single patient. In this scenario, a close collaboration among specialists in selecting the most appropriate operative procedure is essential and brings to better results.
\end{abstract}

( $) 2020$ Elsevier Ltd, BASO The Association for Cancer Surgery, and the European Society of Surgical Oncology. All rights reserved.

\section{Introduction}

Operative endoscopy has become a common therapeutic advancement in clinical practice [1-5], either as a temporary or definitive form of treatment. In selected patients, operative endoscopy has replaced traditional open or laparoscopic surgery. New techniques generate comparisons with established techniques. While medium- and log-term clinical outcomes are well known for traditional surgical techniques, often analysis of the results of new endoscopic operative techniques determine controversies. New technologies as well as deeper experience and expertise bring to continuous improved results, making any comparison source of debate. The positive aspects of the comparisons between endoscopic and surgical techniques can get lost in a field of mere competition when different medical specialties are involved. Several reports have shown the importance of a close collaboration among specialists in the diagnosis and in organizing

\footnotetext{
* Corresponding author.Viale del Policlinico, 00167, Rome, Italy.

E-mail address: antonio.sterpetti@uniroma1.it (A. Lamazza).
}

treatment plans in patients with gastrointestinal diseases [5-7]. The establishment of a colorectal specialist team brings to improved overall results for the medical and surgical treatment of patients with colorectal cancer [8,9]. So far, most of the reports analyzing the results of Self-Expandable Metal Stent (SEMS) in patients with acute and/or subacute malignant left-sided colorectal obstruction have been based on a direct comparison between SEMS placement and different types of surgery [8-11].

In the last 15 years, we have developed a close collaboration between gastroenterologists and surgeons. The colorectal team discusses indications and the most appropriate procedure for each single patient. Not rarely the initial indication is changed after an open and cooperative team discussion. The aim of our study was to analyze the improvement in results determined by the colorectal team collaboration selecting endoscopic placement of colorectal SEMS, we started to use since 199.

\section{Material and Methods}

COLORECTAL ENDOSCOPIC STENTING: In a 16 -year period (August 1999-December 2016), 145 patients with left-sided 
malignant colorectal obstruction had endoscopic placement of SEMS. They were prospectively recorded in a data base. The data base was retrospectively analyzed. The study was approved by the Ethical Committee.

SEMS PLACEMENT: Patients with complete obstruction as determined by preoperative sigmoidoscopy and CT scan, had only a low-pressure water enema few hours before the procedure. If there was no evidence of complete obstruction, a bowel preparation was done: those few patients (less than 10\%) were followed carefully during the bowel preparation, which was immediately stopped in case of abdominal pain. The procedure was performed under light sedation with benzodiazepine, at a dosage depending on patient body weight. A guidewire was passed through the obstruction. In the initial experience, the guidewire was passed blindly through the obstruction, under fluoroscopic and endoscopic guidance. The guidewire was directed towards the obstruction with a colonoscope which remained distally to the tumour, to avoid the risk of perforation. Thanks to the suggestion of an endoscopist (AL), a modified technique has been introduced $[5,6]$. A pediatric nasogastroscope $(4,8 \mathrm{~mm}$ in diameter) has been used to pass the obstruction. This manoeuvre makes possible to have a direct vision of the anatomy and pathology, and to pass the guidewire above the obstruction, through the naso-gastroscope, under direct vision $[3,9]$. This has made the procedure much simpler, faster, and theoretically with reduced risk of perforation or bleeding. Time of exposure to radiation (fluoroscopy) has diminished from 15 to $4 \mathrm{~min}$. The SEMS apparatus (Precision Stent System Microvasive, Boston Scientific Corporation, Boston, USA) is placed at the level of the obstruction, through the guidewire previously inserted, and deployed under fluoroscopic guidance, with a landing zone of $2 \mathrm{~cm}$ above and below the tumour. The length of the stent ranged from 9 to $12 \mathrm{~cm}$. We used mainly uncovered stents: initially Ultraflex OTS stent, lately Wallflex TTS stents (Boston Scientific, Boston, USA). Most of the patients had one stent placed. In 10 patients two stents were required. The diameter of the stent was $24 \mathrm{~mm}$ at least.

Propensity Score Matching: Results were compared for patients who were admitted with left-sided malignant colorectal obstruction in the period in which endoscopic stenting was available (1999-2016) and for patients who were admitted in the previous period (1994-1999) in which endoscopic stenting was not available. The clinical outcomes of eighty patients with left sided malignant obstruction treated from 1994 to 1999 were compared to eighty patients treated in the more recent period. Patients were selected by random sampling within strata: all observations were ranked on their propensity score, and the data were then divided into quantiles of the propensity score. Within each stratum, equal sample sizes in the treatment and control groups were selected. Matching within calipers was proposed to protect against a treated and control observation not similar to each other in their propensity score.

\section{Results}

Mortality and Morbidity after SEMS placement: There was no case of postoperative mortality or major morbidity after SEMS placement. There were no case of bowel perforation or major bleeding. Technical success was obtained in $94.5 \%$ of the 145 patients. In 8 patients it was not possible to pass the guidewire through the obstruction, due to sharp angulation of the obstruction. The procedure was not continued. Surgical colorectal resection or diverting stoma appeared a more appropriate procedure. Clinical success was obtained in $91.8 \%$ of the patients. In 4 patients with ascites and peritoneal implants, despite technical success of stent placement, symptoms of obstruction persisted. In another 10 patients, with ascites and stage IV colorectal cancer, placement of a
Table 1

Propensity score matching left-sided malignant colorectal obstrcution

\begin{tabular}{llll}
\hline Period & $1994-1999$ & $1999-2017$ \\
N Patients & 80 & 80 \\
\hline Primary Resection & 40 & 30 \\
Diverting Stoma & 40 & 10 \\
SEMS Placement & 0 & 40 \\
Mortality & $6 / 80(7.5 \%)$ & $2 / 80(2.5 \%)$ \\
Permanent Stoma & $7 / 80(10 \%)$ & $4 / 80(5 \%)$ \\
MajorComplications & $10 / 80(10 \%)$ & $4 / 80(5 \%)$ \\
Anastomotic Leak & 5 & 1 \\
Wound Infection & 1 & 1 \\
Cardiovascular/Pulmonary & 4 & 2 \\
\hline
\end{tabular}

$\mathrm{P}<0.0001$ Combined Mortality-Morbidity.

stent was not considered appropriate.

Surgical Resection: During the same time period, 60 patients with acute/subacute left-sided malignant colorectal obstruction underwent surgical resection. After consultation between surgeons and gastroenterologists, the option of surgery was considered the safest and best option. Sharp angulation of the rectosigmoid junction, associated to complete bowel obstruction in a patient in good general conditions was considered an indication to surgery. A diverting stoma was preferred in patient with significant proximal colon dilatation. Patients with severe dehydration, electrolyte unbalance, severe co-morbidities were considered for SEMS.

\section{Improved results after the availability of endoscopic stenting}

After the introduction into clinical practice of endoscopic stenting, there was a significant improvement in results. The two matched groups had similar clinical and pathological characteristics.Even if a comparison between two historical periods implies inevitable possibilities of errors, there were no major changes, in term of pre, intra- and post-operative techniques and approaches, other than the possibility to use selectively endoscopic stenting (Table 1).

Follow-up: Patients were followed by the same team who was involved in stent placement. As concern as patients with stage IV colorectal cancer who had definitive stenting, endoscopic re intervention was needed in $28 \%$ of the patients during a mean follow up of 22 months. Most of the complications were related to fecal impaction and they were treated successfully endoscopically.

\section{Discussion}

SEMS placement has been accepted in daily clinical practice [5,9-14]. SEMS offers many theoretical advantages. SEMS placement as a bridge to surgery has the potential to transform an emergency clinical condition into an elective situation. The patient can be treated after correction of electrolyte and fluid unbalance, common in elderly patient with bowel obstruction. A proper bowel preparation and a complete colonoscopy can be performed before surgery [15].

The role of SEMS in this setting has been source of controversies [16,17] Two randomized prospective studies comparing SEMS placement as a bridge to surgery with emergency resection have shown a relatively high technical and clinical failure for stenting $[18,19]$. Four other prospective randomized studies, have shown more favorable results for resection after stenting than for emergency resection $[1,10,20,21]$. Meta analyses have concluded that SEMS stenting in this clinical setting reduces the rate of complications and of permanent stoma formation [22-25]. Five studies analyzed the five-year oncological outcome of patients who had 
resection after SEMS placement and after emergency surgery, and no difference was found in terms of local or distant recurrence between the two groups of patients in four reports [26-30].

In patients with Stage IV colorectal cancer, and symptoms of acute and sub acute obstruction, stenting can represent a valid choice, especially when colorectal resection carries a significant operative risks. Short hospital stay and almost immediate resume of oral feeding can be expected after stenting. Prospective randomized studies and reviews of regional data bases [31,32] comparing stenting versus diverting colostomy have shown lower complication rate and shorter hospital stay in patients who had a stent. In patients with Stage IV obstructing colorectal cancer and good general conditions, surgical resection offers many theoretical advantages in comparison to stenting: conceptually more effective action of chemotherapy [33-35] and prevention of recurrent cancer obstruction, with the possibility of a better quality of life [36].

Several studies [23,37-39] have analyzed the results in patients with Stage IV colorectal cancer who had stenting versus those who had tumor resection. The studies included 837 patients (404 stenting; 433 surgery). Hospital stay and complication rates were significantly lower in the stenting group. Clinical success in relieving the obstruction was higher in the surgery group $(99.8 \%$ versus 93.1\%). Permanent stoma rate was higher in the surgery group (54\% versus 13\%). The overall number of complications was similar in the two groups, but complications in the stent group occurred later. The most common complications in the stent group were re obstruction (18\%), migration (9\%) and perforation (10\%). Median survival in the two groups of patients was similar (7.6 versus 7.8 months). Recent meta analyses have shown that the risk of perforation is not increased in patients with stenting receiving chemotherapy without bevacizumab (7\%) in comparison to patients who had no chemotherapy at all (9\%). Patients who had stenting and chemotherapy with bevacizumab had increased perforation rate (12.5\%) [40-44].

Retrospective studies have shown that technical success for SEMS placement is higher when the operator has performed more than 20 procedures [16,45-48].

Very few papers have focused the attention to a proper collaboration between specialists before and during the SEMS placement.

A close collaboration between surgeons and gastroenterologists allows to determine the most appropriate therapeutic option, avoiding the risk of a difficult SEMS insertion when surgery is a much easier option and vice-versa. Risk factors for technical success of SEMS include complete obstruction, with sharp angulation of the large bowel above the recto sigmoid junction. The blind passage of the guidewire, can lead to the perforation of the large bowel wall which, above the obstruction, is thin, dilated, and partially ischemic. Colorectal stenting, as suggested by the European Society for Gastrointestinal Endoscopy is more difficult, with a higher possibility for stent dislodgment, in the right and transverse colon. It is very difficult to place the stent in the right position in these anatomic locations, and the risk for complications is high.

\section{Conclusions}

The therapeutic options in patients with acute or subacute malignant colorectal obstruction, including endoscopic placement of a stent, should be based on a careful analysis of the different risk factors. In this scenario, a close collaboration among specialists in selecting the most appropriate operative procedure, is essential and brings to better results. SEMS placement, surgical resection or simple diverting stoma should be considered complementary techniques to be used according to the specific clinical situation and experience of the involved colorectal team.

\section{Funding}

No funds were received for this work.

\section{Declaration of competing interest}

None of the authors has conflicts of interest to declare.

\section{References}

[1] Arezzo A, Balague C, Targarona E, et al. Colonic stenting as a bridge to surgery versus emergency surgery for malignant colonic obstruction: results of a multicentre randomised controlled trial (ESCO trial). Surg Endosc 2017;31: 3297-305.

[2] Spannenburg L, Sanchez Gonzalez M, Brooks A, Wei S, Li X, Liang X, et al. HSurgical outcomes of colonic stents as a bridge to surgery versus emergency surgery for malignant colorectal obstruction: a systematic review and metaanalysis of high quality prospective and randomised controlled trials. Eur J Surg Oncol 2020 May 7;(20):S0748-7983. https://doi.org/10.1016/ j.ejso.2020.04.052. 30449-2.

[3] Lamazza AFiori E, Schillaci A, Demasi E. Sterpetti AV "Self expandable metal stents in patients with stage IV unresectable colorectal cancer " World. J Surg 2012:36:2931-6.

[4] Lordan JT, Karanjia ND, Quiney N, Fawcett WJ. Worthington TR-A 10-year study of outcome following hepatic resection for colorectal liver metastases - the effect of evaluation in a multidisciplinary team setting. Eur J Surg Oncol 2009 Mar;35(3):302-6. https://doi.org/10.1016/j.ejso.2008.01.028.

[5] Rostoft S, Hamaker ME. Basic geriatric principles for colorectal surgeons: how to optimize assessment and care of older patients in the perioperative period. Eur J Surg Oncol 2020 Mar;46(3):310-5. https://doi.org/10.1016/ j.ejso.2019.07.027.

[6] van de Velde CJ, Boelens PG Tanis PJ, Espin E, Mroczkowski P, Naredi P, et al. Experts reviews of the multidisciplinary consensus conference colon and rectal cancer 2012: science, opinions and experiences from the experts of surgery. Eur J Surg Oncol 2014 Apr;40(4):454-68. https://doi.org/10.1016/ j.ejso.2013.10.013. Epub 2013 Nov 8.

[7] Keller DS, Berho M, Perez RO, Wexner SD, Chand M. The multidisciplinary management of rectal cancer. Nat Rev Gastroenterol Hepatol 2020 Mar 12. https://doi.org/10.1038/s41575-020-0275-y. Online ahead of print.PMID: 32203400 Review.

8] Myint AS, Gérard JP. -Role of radiotherapy in the treatment of rectal cancer in older patients. Eur J Surg Oncol 2020 Mar;46(3):349-57. https://doi.org/ 10.1016/j.ejso.2019.12.017.

[9] Lamazza A, Sterpetti AV, Fiori E. Endoscopic placement of self-expanding stents in patients with symptomatic leakage after colorectal resection for cancer: long term results. Endoscopy 2015;47:270-2.

[10] Saito S, Yoshida S, Isayama $\mathrm{H}$, et al. A prospective multicentre study on selfexpandable metallic stents as a bridge to surgery for malignant colorectal obstruction in Japan: efficacy and safety in 392 patients. Surg Endosc 2016;30: 3976-86.

[11] Atukorale YN, Church JL, Hoggan BL, Lambert RS, Gurgacz SL, Goodall S, et al. Self-expanding metallic stents for the management of emergency malignant large bowel obstruction: a systematic review". J Gastrointest Surg 2016;20: 455-62.

[12] Abelson JS, Yeo HL, Mao J, Milsom JW, Sedrakyan A. Long-term postprocedural outcomes of palliative emergency stenting vs stoma in malignant large-bowel obstruction. JAMA Surg 2017;152:429-35.

[13] Saida Y, Enomoto T, Takabayashi K, et al. Outcome of 141 patients of self expandable metallic stent placements for malignant and benign colorectal strictures in a single center. Surg Endosc 2011;25:1748-52.

[14] Veld JV, Amelung FJ, Borstlap WAA, van Halsema EE, Consten ECJ, Siersema PD, et al. Dutch snapshot research group. Comparison of decompressing stoma vs stent as a bridge to surgery for left-sided obstructive colon cancer. JAMA Surg 2020 Jan 8;155(3):206-15. https://doi.org/10.1001/ jamasurg.2019.5466.

[15] Kodeda K, Nathanaelsson L, Jung B, Olsson H, Jestin P, Sjovall P, et al. Population-base data from the Swedish colon cancer registry". Br J Surg 2013;100: $1100-7$.

[16] van Hooft JE, van Halsema EE, Vanbierbvie G, et al. European society of gastrointestinal endoscopy "self expandable metal stents for obstructing colonic and extracolonic cancer: European society of gastrointestinal endoscopy-clinical guideluines" gastrointestinal. Endoscopy 2014;80:747-61.

[17] van Halsema EE, van Hooft JE. Should we reconsider the use of self expandable metal stents as a bridge to surgery in malignant colorectal obstruction? Endoscopy 2015;47:481-2.

[18] van Hooft JE, Bemelman WA, Oldenburg B, et al. Colonic stenting versus emergency surgery for acute left-sided malignant colonic obstruction: a multicentre randomised trial. Lancet Oncol 2011;12:344-52.

[19] Pirlet IA, Slim K, Kwiatkowski F, Michot F, Millat BL. Emergency preoperative stenting versus surgery for acute left-sided malignant colonic obstruction: a multicenter randomized controlled trial. Surg Endosc 2011;25:1814-21.

[20] Cheung HY, Chung CC, Tsang WW, Wong JC, Yau KK, Li MK. Endolaparoscopic 
approach versus conventional open surgery in the treatment of obstructing left-sided colon cancer : a prospective randomized trial". Arch Surg 2009;144: $1127-32$.

[21] Ho KS, Quah HM, Lim JF, Tang CL, Eu KW. Endoscopic stenting and elective surgery versus emergency surgery for left-sided malignant colonic obstruction: a prospective randomized trial". Int J Colorectal Dis 2012;7:355-62. https://doi.org/10.1007/s00384-011-1331-4.

[22] Arezzo A, Passera R, Lo Secco G, Verra M, Bonino MA, Targarona E, et al. Stent as a bridge to surgery for left-sided malignant colonic obstruction reduces adverse events and stoma rate compared with emergency surgery: results of a systematic review and meta analysis of randomized trials. Gastrointest Endosc 2017;86:416-26. https://doi.org/10.1016/j.gie.2017.03.1542.

[23] Liang TW, Sun Y, Wei YC, Yang DX. Palliative treatment of malignant colorectal obstruction caused by advanced malignancy : a self expanding metal stent or surgery?: a systematic review and meta analysis. Surg Today 2014 Jan;44(1):22-33. https://doi.org/10.1007/s00595-013-0665-7.

[24] Baer C, Menon R, Bastawrous S, Bastawrous A. Emergency presentations of colorectal cancer. Surg Clin 2017;97:529-45.

[25] Amelung FJ, Borstlap WAA, Consten ECJ, et al. Propensity score-matched analysis of oncological outcome between stent as bridge to surgery and emergency resection in patients with malignant left-sided colonic obstruction. Br J Surg 2019 Jul:106(8):1075-86, https://doi.org/10.1002/bjs.11172.

[26] Erichsen R, Horwath Puho E, Jacobsen JB, Nilsson T, Baron JA, Sorensen HT. Long term mortality and recurrence after colorectal cancer surgery with preoperative stenting : a Danish nationwide cohort study". Endoscopy 2015;47:517-24.

[27] Matsuda A, Miyashita M, Matsumoto S, et al. Comparison of long term outcomes of colonic stents as a "bridge to surgery" and emergency surgery for malignant large-bowel obstruction: a meta-analysis". Ann Surg Oncol 2015;22:497-504

[28] Lim TZ, Chan DKH, Tan KK. Endoscopic stenting does not worsen long term outcome amongst patients presenting with obstruction from colorectal cancers “. Ann Surg Oncol 2017;24:1618-25.

[29] Ceresoli M, Allievi N, Coccolini F, et al. Long-term oncologic outcomes of stent as a bridge to surgery versus emergency surgery in malignant left side colonic obstructions: a meta-analysis. J Gastrointest Oncol 2017;8:867-76. https:// doi.org/10.21037/jgo.2017.09.04.

[30] Foo CC, Poon SHT, Chiu RHY, Lam WY, Cheung LC, Law WL. Is bridge to surgery stenting a safe alternative to emergency surgery in malignant colonic obstruction: a meta-analysis of randomized control trials. Surg Endosc 2019;33:293-302. https://doi.org/10.1007/s00464-018-6487-3.

[31] Abelson JS, Yeo HL, Mao J, Milsom JW, Sedrakyan A. Long term postprocedural outcomes of palliative emergency stenting versus stoma in malignant largebowel obstruction. JAMA Surg 2017 May 1;152(5):429-35. https://doi.org/ 10.1001/jamasurg.2016.5043.

[32] van Hooft JE, Veld JV, Arnold D, et al. Self-expandable metal stents for obstructing colonic and extracolonic cancer: European Society of Gastrointestinal Endoscopy (ESGE) Guideline - update 2020. A.Endoscopy. 2020 May;52(5):389-407. https://doi.org/10.1055/a-1140-3017. Epub 2020 Apr 7.

[33] van Rooijen KL, Shi O. Goey KKH et al 1 Prognostic value of primary tumour resection in synchronous metastatic colorectal cancer: individual patient data analysis of first-line randomised trials from the ARCAD database. Eur J Canc 2018;91:99-106. https://doi.org/10.1016/j.ejca.2017.12.014.

[34] Tsang WY, Ziogas A, Lin BS, Seery TE, Karnes W, Stamos MJ, et al. Role of primary tumor resection among chemotherapy-treated patients with synchronous stage IV colorectal cancer: a survival analysis. J Gastrointest Surg 2014 Mar;18(3):592-8. https://doi.org/10.1007/s11605-013-2421-0.
[35] Faron M, Pignon JP, Malka D, Bourredjem A, Douillard JY, Adenis A, et al. Is primary tumour resection associated with survival improvement in patients with colorectal cancer and unresectable synchronous metastases? A pooled analysis of individual data from four randomised trials. Eur J Canc 2015 Jan;51(2):166-76. https://doi.org/10.1016/j.ejca.2014.10.023.

[36] Tomita M, Saito S, Makimoto S, Yoshida S, Isayama H, Yamada T, et al. Selfexpandable metallic stenting as a bridge to surgery for malignant colorectal obstruction: pooled analysis of 426 patients from two prospective multicenter series. Surg Endosc 2019;33:499-509. https://doi.org/10.1007/s00464-0186324-8.

[37] Zhao XD, Cai BB, Cao RS, Shi RH. Palliative treatment for incurable malignant colorectal obstructions: a meta-analysis. World J Gastroenterol 2013;19: 5565-74. https://doi.org/10.3748/wjg.v19.i33.5565.

[38] Kim BC, Han KS, Hong CW, Sohn DK, Park JW, Park SC, et al. Clinical outcomes of palliative self-expanding metallic stents in patients with malignant colorectalobstruction. J Dig Dis 2012;13:258-66. https://doi.org/10.1111/j.17512980.2012.00564.x.

[39] Allievi N, Ceresoli M, Fugazzola P, Montori G, Coccolini F, Ansaloni L. Endoscopic stenting as bridge to surgery versus emergency resection for left-sided malignant colorectal obstruction: an updated meta-analysis. Int J Surg Oncol 2017;2017:2863272. https://doi.org/10.1155/2017/2863272.

[40] van Halsema EE, van Hooft JE, Small AJ, Baron TH, García-Cano J, Cheon JH et al. Perforation in colorectal stenting: a meta-analysis and a search for risk factors. Gastrointest Endosc 2014;79:970-82. https://doi.org/10.1016/ j.gie.2013.11.038. e doi.

[41] Small AJ, Coelho-Prabhu N, Baron TH. Endoscopic placement of selfexpandable metal stents for malignant colonic obstruction: long-term outcomes and complication factors. Gastrointest Endosc 2010;71:560-72. https://doi.org/10.1016/j.gie.2009.10.012.

[42] Choi JH, Lee YJ, Kim ES, Choi JH, Cho KB, Park KS, et al. Covered selfexpandable metal stents are more associated with complications in the management of malignant colorectal obstruction. Surg Endosc 2013;27: 3220-7. https://doi.org/10.1007/s00464-013-2897-4.

[43] Tominaga K, Maetani I, Sato K, Shigoka H, Omuta S, Ito S, et al. Favorable longterm clinical outcome of uncovered D-weave stent placement as definitive palliative treatment for malignant colorectal obstruction. Dis Colon Rectum 2012;55:983-9. https://doi.org/10.1097/DCR.0b013e31825c484d.

[44] Gallo G, Ammendola M, Colace R, Sacco R, Sammarco G. Bridge to surgery in patients with obstructive colorectal cancer Comparison of covered and uncovered stents. Ann Ital Chir 2017;88. pii: S0003469X17025751.

[45] Arezzo A, Bini R, Lo Secco G, Verra M, Passera R The role of stents in the management of colorectal complications: a systematic review. Surg endosc. 2017; 31:2720-2730. doi: 10.1007/s00464-016-5315-x.

[46] Park YE, Park Y, Park SJ, Cheon JH, Kim WH, Kim TI. Outcomes of stent insertion and mortality in obstructive stage IV colorectal cancer patients through 10 year duration.Surg Endosc. 2019; vol. 33: 1225-1234. doi: 10.1007/s00464-018-6399-2.

[47] Lee JH, Yoon JY, Park SJ, Hong SP, Kim TI, Kim WH, et al. The learning curve for colorectal stent insertion for the treatment of malignant colorectalobstruction. Gut Liver 2012;6:328-33. https://doi.org/10.5009/ gnl.2012.6.3.328

[48] Lamazza A, Fiori E, Sterpetti AV, Schillaci A, De Cesare A, Lezoche E. Endoscopic placement of self-expandable metallic stents for rectovaginal fistula after colorectal resection: a comparison with proximal diverting ileostomy alone. Surg Endosc 2016;30:797-801. https://doi.org/10.1007/s00464-0154246-2. 